\title{
CONTRIBUTO DA METODOLOGIA DE CUIDADO HUMANITUDE PARA A GESTÃO DAS EMOÇÕ̃ES NA PANDEMIA
}

\author{
Andréa Temponi dos Santos \\ Faculdade de Medicina de Jundiaí - Brasil \\ atemponi@gmail.com \\ Rosa Cândida Carvalho Pereira de Melo \\ Unidade de Investigação em Ciências da Saúde: Enfermagem, da Escola Superior de Enfermagem de Coimbra \\ rosamelo@esenfc.pt \\ Liliana Vanessa Lúcio Henriques \\ Unidade de Investigação em Ciências da Saúde: Enfermagem, da Escola Superior de Enfermagem de Coimbra \\ lilianahenriques312@gmail.com \\ Beatriz Temponi \\ Faculdade de Medicina de Jundiaí - Brasil \\ beatemp@gmail.com \\ Amélia Martins \\ Cooperativa Hominis CRL, Instituto Gineste Marescotti (IGM) Portugal \\ ameliacsp@gmail.com \\ Evaldo Marchi \\ Faculdade de Medicina de Jundiaí - Brasil \\ evmarchi@uol.com.br
}

Recepción Artículo: 13 mayo 2021 Admisión Evaluación: 13 mayo 2021 Informe Evaluador 1: 26 mayo 2021 Informe Evaluador 2: 28 mayo 2021 Aprobación Publicación: 02 junio 2021

\section{RESUMO}

As emoções possuem um forte impacto sobre as nossas percepções, nossas memórias, nossos pensamentos, nossa capacidade de ajuizamento e sobre o nosso comportamento. A compreensão dos comportamentos e das emoções manifestadas pela pessoa cuidada, nomeadamente em situação de fragilidade e de vulnerabilidade, é fundamental para o seu bem-estar, sendo importante a implementação de metodologias de cuidado promotoras de sentimentos positivos, por parte dos cuidadores. 0 objetivo deste estudo foi descrever as emoções percebidas pela direção de 6 residências para idosos no período de confinamento, devido à pandemia COVID-19, e identificar os contributos da Metodologia de Cuidado Humanitude (MCH) para a gestão dessas emoç̃ões. Realizou-se um estudo multicasos descritivo, sendo os dados coletados por meio de entrevistas semiestruturadas, realizadas com um membro da direção técnica de cada uma das residências. Foi realizada análise de conteúdo, aos dados obtidos, seguindo o modelo de Bardin, sendo organizados em categorias e subcategorias. Foram evidenciadas as seguintes emoções negativas: tristeza, apreensão, menosprezo, ansiedade e indignação, percebidas pelas diri- 


\section{CONTRIBUTO DA METODOLOGIA DE CUIDADO HUMANITUDE PARA A GESTÃO DAS EMOÇ̃̃ES NA PANDEMIA}

gentes, tanto nos profissionais quanto nas pessoas cuidadas no período de confinamento frente à pandemia do COVID-19. Porém, houve a percepção de que a implementação dos principios da MCH, contribuiu para a minimização de emoções negativas e potenciou emoções positivas gerando mais otimismo, confiança e alegria em todos os envolvidos. Torna-se, pois, fundamental a apropriação dos principios da MCH, por parte dos cuidadores, facilitadores da interação com a pessoa cuidada, promovendo sentimentos de bem-estar, mesmo em situação de grande vulnerabilidade e fragilidade, como é o caso da pandemia por COVID-19, vivenciada pelos idosos institucionalizados.

Palavras-chave: humanização da assistência; emoções; regulação emocional; idoso

\section{ABSTRACT}

Contribution of the humanitude care methodology to the management of emotions in pandemia. Emotions have a strong impact on our perceptions, our memories, our thoughts, our ability to judge and even, on our behavior. Understanding the behaviors and emotions manifested by the person being cared for, particularly in situations of fragility and vulnerability, is fundamental to their well-being, and it is important for caregivers to implement care methodologies that promote positive feelings. The aim of this study was to describe the emotions perceived by the management of 6 residences for the elderly in the confinement period, due to the COVID-19 pandemic, and to identify the contributions of the Humanitude Care Methodology (HCM) for the management of these emotions. A descriptive multi-case study was carried out, with data collected through semistructured interviews, carried out with a member of the technical management of each of the residences. Content analysis was performed on the data obtained, following the Bardin model, being organized into categories and subcategories. The following negative emotions were evidenced: sadness, apprehension, contempt, anxiety and indignation, perceived by the managers both in the professionals and in the people cared for during the confinement period in the face of the COVID-19 pandemic. However, there was also the perception that the implementation of the principles of $\mathrm{HCM}$, contributed to the minimization of negative emotions and potentiated positive emotions generating more optimism, confidence and joy in everyone involved. It is therefore essential that the caregivers take ownership of the principles of HCM, facilitators of interaction with the person being cared for, promoting feelings of well-being, even in situations of great vulnerability and fragility, as is the case of the pandemic by COVID-19, experienced by institutionalized elderly.

Keywords: humanization of assistance; emotions; emotional regulation; elderly

\section{INTRODUÇÃO}

Humanitude é o conjunto de particularidades que fazem com que sintamos pertencentes à espécie humana e reconhecemos o outro ser humano como pertencente à nossa espécie (Henriques, Dourado, Melo \& Tanaka, 2019).

Yves Gineste e Rosette Marescotti desenvolveram a Metodologia de Cuidado Humanitude (MCH) ou Metodologia Gineste-Marescotti (MGM) a partir das inquietações sobre a forma como os cuidados diários às pessoas dependentes e vulneráveis estavam sendo prestados no que dizia respeito à dignidade, à liberdade e à autonomia. Nesta métodologia, a realização dos procedimentos na prestação de cuidados fundamenta-se em quatro pilares: 0 olhar, que permite estabelecer a ligação com a pessoa dando-Ihe atenção, mostrando uma relação de igualdade, devendo ser axial, horizontal, longo e próximo; a palavra, que deve ser suave, melodiosa, grave, anunciadora e descritiva; o toque, que deve ser amplo e pacificador, realizado com suavidade ou "toque-ternura", progressivo e permanente, evitando pegar em garra ou em pinça; a verticalidade, deve ser promovido ao longo de todos os cuidados "viver e morrer de pé", pelos benefícios que promove ao funcionamento de todo o organismo e ser uma das principais características da espécie humana (Simões, 2013).

A MCH tem vindo a revelar inúmeros ganhos na recuperação da qualidade de vida de doentes idosos acamados, com demência e outras situações de fragilidade. Este conceito mostra-nos como comportamentos e ações simples 
podem ser fundamentais na comunicação e no relacionamento interpessoal, e que vão ao encontro do ser no que el tem de mais essencialmente humano (Phaneuf, 2007; Pereira, Gomes \& Galvão, 2012).

Segundo Simões, Salgueiro e Rodrigues (2012) a aplicação da MCH aos cuidados de enfermagem se traduz num ganho de bem-estar entre os idosos, o qual se estende aos profissionais, levando a um aumento da satisfação e do sentimento de realização profissional.

Neste momento pandémico, porém, o bem-estar de muitas pessoas se abalou. Dado o elevado potencial de contágio, por via aérea, através de gotículas (Zhang, Wu, Zhao, \& Zhang, 2020), foram adotadas medidas preventivas em todos os países, seguindo as orientações da Organização Mundial de Saúde (OMS), como o confinamento, o distanciamento social e a utilização dos Equipamentos de Proteção Individual (EPl's), tais como: respiradores N95, óculos, protetores faciais e luvas, de forma a garantir a proteção dos profissionais de saúde (Teixeira et al., 2020).

Nesse contexto, os idosos foram dos que mais sofreram, em nome das medidas de segurança, gerando insegurança e medo em todos os envolvidos no cuidado.

0 prestador de cuidados, por sua vez, no desempenho das suas funções, vive momentos de forte intensidade emocional partilhados com o idoso. Nessa troca de emoções percebidas e sentidas é aberto um espaço de partilha humana, bastante afastado dos discursos racionais ou científicos e sem soluções para as dificuldades vivenciadas (Rispali, 2003).

Ao longo de anos estudando as emoções, o psicólogo americano Dr. Robert Plutchik propôs que existem oito emoções primárias que servem de base para todas as outras: alegria, tristeza, confiança, nojo, medo, raiva, surpresa e antecipação. Plutchik (2002), elaborou em 1980, a "roda das emoções" que se baseia nos critérios de tipologia, antagonismo e intensidade. Quanto à tipologia, o autor define as emoções em básicas (alegria, confiança, medo, surpresa, tristeza, nojo, raiva e antecipação) e compostas ou secundárias (combinação das emoções básicas que dá lugar a um total de vinte e quatro emoções compostas, classificadas em três díades: primária, secundária e terciária). Também refere que as emoções se encontram situadas dependendo do seu grau de similaridade e discrepância; aquelas mais similares estão próximas e as mais antagônicas estão localizadas em oposição uma à outra (quatro eixos de oposição: alegria - tristeza; antecipação - surpresa; nojo - confiança; raiva - medo).

Este estudo teve como base a teoria de Plutchik (2002), com o intuito de descrever as emoções percebidas pelos dirigentes relacionadas à pandemia e o contributo da MCH na gestão dessas emoções na pandemia.

\section{OBJETIVOS DA INVESTIGAÇÃO}

0 objetivo deste estudo foi descrever as emoções percebidas pela direção de 6 residências para idosos no período de confinamento, devido à pandemia do COVID-19, e identificar o contributo da Metodologia de Cuidado Humanitude (MCH) para a gestão

dessas emoções.

\section{AMOSTRA}

Os participantes que constituíram a amostra foram seis diretoras técnicas das seis Estruturas Residenciais para Pessoas Idosas (ERPI) em Portugal, que cumpriam os

critérios de inclusão, nomeadamente terem formação em Humanitude, experiência em cuidar de idosos em situação de pandemia por COVID -19 e aceitar participar da recolha de dados por meios digitais.

Os participantes são oriundos das seguintes áreas: 3 Assistentes sociais, 1 Enfermeira, 1 Licenciada em Educação e 1 Psicóloga.

A idade das participantes variou de 40 a 54 anos de idade, sendo todas do sexo feminino. 


\section{CONTRIBUTO DA METODOLOGIA DE CUIDADO HUMANITUDE PARA A GESTÃO DAS EMOÇÕES NA PANDEMIA}

\section{METODOLOGIA}

Realizou-se um estudo multicasos descritivo, com abordagem qualitativa, sendo os dados coletados por meio de entrevistas semiestruturadas, realizadas a um membro da direção técnica de cada uma das seis ERPI's, via online, pela plataforma Zoom, tendo a duração de 40 minutos a 1 hora. Para a seleção da ERPI teve-se em conta 0 critério de ser uma instituição com reconhecimento de unidade Humanitude.

Para o tratamento dos dados obtidos realizou-se análise de conteúdo segundo Bardin (2016), sendo organizados em categorias e subcategorias, com o contributo de

investigadores peritos na área. Para a análise dos resultados, na categorização das respostas às questões colocadas aos dirigentes destas instituições, foi utilizado 0

software Atlas.ti para análise qualitativa de dados, sendo organizados em categorias e subcategorias, utilizando as terminologias da BVS-Psi para a definição das categorias e as emoções segundo a teoria de Plutchik (2002) para as subcategorias.

As categorias relacionadas foram: emoções relacionadas à pandemia e os contributos da $\mathrm{MCH}$ no manejo das emoções durante 0 confinamento.

A cada instrumento de recolha de dados foi atribuído um número de código, para se ordenar e organizar 0 material devidamente, com o intuito de se trabalhar os dados obtidos.

Os critérios de inclusão definidos para este estudo foram os entrevistados serem profissionais com cargo de gestão e terem realizado formação sobre a Metodologia de

Cuidado Humanitude em instituições que realizaram a formação na MCH com seus colaboradores.

Foram considerados os aspetos éticos, como a assinatura de uma declaração de consentimento informado, sendo garantido o caráter voluntário da sua participação e assegurada inteira liberdade de participar ou não da pesquisa. Essa obteve o parecer favorável no P726/11-2020 da Comissão de Ética da Unidade de Investigação em Ciências da Saúde: Enfermagem, da Escola Superior de Enfermagem de Coimbra.

\section{RESULTADOS ALCANÇADOS}

Da análise de conteúdo emergiram duas categorias: emoções negativas percebidas em relação à pandemia e 0 contributo da MCH na gestão das emoções durante o confinamento frente à pandemia.

\section{Emoções negativas percebidas em relação à pandemia}

Da categoria emoções percebidas em relação à pandemia emergiram 4 subcategorias: emoções básicas (medo, tristeza, angústia, nojo, tédio, aborrecimento, antecipação e vigilância), emoções compostas/díade primária (desprezo e agressividade), emoções compostas/díade secundária (fatalismo, desespero e descrença) e emoções compostas/díade terciária (ansiedade e pessimismo).

Em relação às emoções básicas, a maioria das dirigentes percebeu essas emoções como negativas. Várias dirigentes referiram o medo como uma emoção presente no período do cofinamento: "eu acho que o nosso medo é muito grande, nós sentimos todos muito medo e às vezes o medo também nos paralisa." (E1); "a determinada altura andávamos todos sem norte e isso assustou-nos imenso...julgo que eles também tiveram muito receio de nunca mais nos conseguirem abraçar." (E2); "este medo vinha, por mais que eu não quisesse pensar nele" (E4); "medo, muito medo, porque houve por exemplo

2 utentes que os problemas de saúde agravaram... não queriam sair daqui para ir ao hospital, porque tinham medo de ficar contaminadas... dizia que tinha medo de apanhar a doença do COVID, tinha medo de ficar abandonada, porque ninguém podia ir lá ter." (E5).

Outras emoções negativas percebidas pelas dirigentes foram a tristeza e a angústia, conforme os seguintes discursos: "a tristeza foi evidente, a questão de terem que estar o mais confinados possível ao quarto, retirouIhes este convívio, esta sensação de solidão foi desastrosa... 0 sentimento de abandono por parte da família foi complicado, porque alguns não percebiam porque é que os filhos não os iam ver, nas videochamadas muitos deles não conseguiam ver a família, não conseguiam perceber quem estava do outro lado, não se conseguia man- 
ter a relação, era impossível, foi muito duro para eles...Para as famílias, foi muito doloroso este afastamento também em relação aos idosos, porque não podiam visitar os seus entes queridos." (E2); "percebia-se que a ausência de verem os filhos, muitos não percebiam o que se estava a passar e isso refletiu-se numa tristeza que se percebia." (E4); " a senhora não faleceu da doença, faleceu realmente da saudade, de tristeza... com os colaboradores por sua vez 0 impacto é muito forte, porque às vezes nós tínhamos que disfarçar em frente aos utentes...tínhamos que estar sempre no melhor de nós, e não é fácil. Estou numa fase em que me sinto cansada, um misto de tristeza...houve quem tivesse que tomar medicação antidepressiva." (E5); "porque nós já sabemos que a depressão também ela é uma perda, porque as pessoas começam a perder capacidade, e isso nós notamos nos nossos cuidadores e nas pessoas cuidadas." (E6).

Quanto à angústia uma das dirigentes descreveu: "as duas utentes que faleceram o ano passado, logo no inicio no mês de abril, não faleceram com COVID, mas por causa da privação da família, tinham familiares muito presentes e com a situação da pandemia foram proibidas as visitas." (E5).

Emoções como o nojo e o tédio, também foram referidas pela direção: "às vezes já sinto o desgaste do viver, aquilo que eu sinto é, eu vivo para os meus, minha casa e para o trabalho. É um certo tédio, inclusive, que é uma emoção poderosa,

o nojo, a repugnância de algumas coisas." (E6); "estão há um ano fechados basicamente, as visitas são distantes, com uma barreira física no meio, não é a mesma coisa por vídeo-chamada, eu acho que não há nada que 0 olhar e 0 toque substitua."(E6).

As dirigentes relataram aborrecimento, que é uma emoção mais abrandada da raiva e também relataram indignação: "é uma tortura para os idosos o que estamos a fazer, por um acrílico entre eles, eles não compreendem porque os estamos a separar." (E2); "Ao nível da implementação da Humanitude também teve um impacto..., porque o lar estava praticamente fechado, não estava aberto às visitas." (E6); "até que ponto era uma relação em Humanitude quando a gente não pode tocar, ou quando nós temos que evitar no máximo do possível o toque, no início realmente questionávamo-nos muito." (E3); "Os idosos ficaram mais agressivos, mais inquietos, mais agitados, houve um grande impacto...as famílias, muitas vezes, reagiam com alguma agressividade em relação à própria instituição, e alguma incompreensão de exigências, porque talvez elas próprias estavam revoltadas" (E2).

As preocupações, em forma de antecipação também foram referidas, conforme pode ser observado nos depoimentos das dirigentes: "inicialmente eu estava muito

preocupada porque toda a formação da equipa foi sempre no sentido do toque e a pandemia vem nos dizer, não toquem! afastem-se!" (E1); "chegamos a um ponto que achávamos que estávamos numa outra instituição, parece que não nos reconhecíamos, e foi duro porque no ano em que dispara o COVID no nosso país e no mundo inteiro era um ano que seria para consolidação da aprendizagem da MCH." (E2); "entramos nesta nova conjuntura, e neste novo paradigma, aí a equipa desmembrou-se completamente...a rotatividade do pessoal...não percebiam o porquê duma cara nova...o afastamento com que estavam gerava essa preocupação, essa desconfiança." (E4); "Realmente uma antecipação geral, um processo de ansiedade... A forma mais intensa da preocupação, a vigilância, também foi percebida por uma dirigente que referiu: "0 que se notava é que no início da semana tinham mais leveza, porque começavam à segunda-feira e ficavam até segunda-feira da semana seguinte...depois no final da semana quase que se tornava uma indústria." (E5).

Além das emoções básicas, também foram percebidas emoções compostas como a descrença, desespero, fatalismo, ansiedade, pessimismo e desprezo. A emoção descrença durante o período do confinamento foi evidenciada a partir do depoimento: "os nossos residentes, estavam efetivamente com um nível de bem-estar que nos agradava imenso, sentíamo-nos muito realizados com esta evolução, sentíamos que efetivamente estávamos num lugar de vida como preconiza a Humanitude e de repente o COVID obriga-nos a mudar o foco...0 COVID veio estragar tudo outra vez" (E2). 0 desespero foi referido a partir dos seguintes comentários: "Desânimo, descrédito, incerteza, confusão, medo muito medo, muita apreensão, fadiga emocional e física e muita revolta." (E2); "julgo que neste período que houve o maior afastamento da família, um período em que havia muitos medos, viveu-se uma angústia de a todo o momento acontecer connosco, e de não voltarem a ver os seus familiares." (E4). 


\section{CONTRIBUTO DA METODOLOGIA DE CUIDADO HUMANITUDE PARA A GESTÃO DAS EMOÇ̃̃ES NA PANDEMIA}

Quanto ao fatalismo, observou-se os seguintes discursos: "os autônomos e cognitivamente bem, diziam porque é que eu que estou institucionalizado não posso ter uma vida normal e os que estão lá fora podem-na ter, não conseguiam perceber isto...nós vamos morrer de qualquer coisa porque estão preocupados, se formos do COVID vai ser de COVID" (E2).

Quanto à ansiedade, uma das dirigentes testemunhou: "algumas estavam obviamente muito mais angustiadas e ansiosas...mas eu reconheço que foram muitos desafios ao mesmo tempo, que me levaram a chegar ao final do ano num esgotamento tremendo, isso eu confesso e estou ainda a recuperar...foi muito desgastante." (E4).

Nos comentários relacionados ao pessimismo, foi referido que: "Protege-se a pessoa cuidada da COVID e exponencia-se o risco da pessoa cuidada a uma série de outros problemas, e o cuidador também. A situação pandêmica vai ter impactos muito maiores a longo prazo, 0 impacto social, emocional, o impacto econômico vai ser brutal ...e isso em termos psicoemocionais vai ser ainda pior... Acho que indiretamente a pandemia condiciona 0 processo de implementação da Humanitude, por muito que nós não queiramos... acaba sempre por interferir."(E6).

0 desprezo foi evidenciado através do discurso de uma das dirigentes: "numa fase inicial eu acho que estava toda a gente com uma grande motivação...e nota-se agora um esgotamento nessa motivação...uma falta de interesse." (E6).

\section{Contributo da MCH na gestão das emoções durante a pandemia}

Da categoria contributo da $\mathrm{MCH}$ na gestão das emoções durante 0 confinamento emergiram 2 subcategorias: emoções básicas positivas (alegria, serenidade, confiança, aprovação e interesse) e emoções compostas positivas/díade primária (amor e otimismo).

As dirigentes perceberam com alegria que a metodologia foi fundamental na

manutenção de emoções positivas durante 0 confinamento: "o toque e 0 olhar foram fundamentais, e como estavam tão treinados tiveram muito bons resultados na transmissão de emoções positivas." (E2); "acho que ainda assim com esse lugar de família que conseguimos construir na instituição, e também porque fomos criando estratégias de proximidade, acho que se encontrou esse lugar de vida" (E4). A serenidade também foi referida: "A questão da Humanitude foi de tornar a instituição como um lar, ou seja, um local onde as pessoas também gostassem de estar, tal como gostamos de estar na nossa casa, porque é o nosso lar." (E5).

Várias referências foram feitas em relação à confiança e à aprovação relacionadas à MCH, o que demonstra aceitação, no sentido de se sentir parte de um grupo, recebendo cuidado e carinho: "eu acho que a grande vantagem é que a equipa apoia-se muito, ajudam-se muito internamente e portanto elas próprias afastam o medo umas das outras." (E1); "afinal nós ainda temos Humanitude, e foi aí que eu comecei a dizer às colegas vamos ter esperança e fé e acreditar que a Humanitude não desapareceu da nossa casa...eu acredito que teríamos muito mais perdas, até do ponto de vista da equipa de cuidadores, porque lutaram efetivamente pelos seus residentes, elas puseram em causa a vida familiar delas para estarem com eles." (E2); "desde o momento que todos os colaboradores deram o máximo de si para minimizar o isolamento/afastamento das famílias demos espaço para minimizar as suas mágoas e angústias." (E3). Foi ainda enfatizada a confiança nos princípios da $\mathrm{MCH}$, conforme os seguintes discursos: "eu não me senti sem rumo, porque eu percebia que se nós acreditássemos no que estávamos a fazer poderíamos conseguir passar isto da melhor forma possível." (E4); "os princípios não se perderam com a pandemia nem com a mudança da equipa, o global destaque esta lá." (E5); "nós criamos um grupo pro no WhatsApp $®$ dos profissionais...eu fazia montagens de fotografias motivacionais, eu acho que a Humanitude e o confinamento fizeram isto." (E6); "uma metodologia que nos diz como fazer, mesmo quando em situação de pandemia....nós conseguimos perceber que temos que nos proteger e seguir procedimentos de desinfecção, mas a relação tem que estar lá sempre, e por isso acho que até aí nos ajudou a nós percebermos que vamos continuar a cuidar da mesma forma." (E1); "a Humanitude centra-se no que a pessoa quer e no que a pessoa sente, e não naquilo que nós achamos que a pessoa deve querer, eu acho que a mudança de perspectiva é muita esta." (E6). 
0 interesse na utilização dos vários pilares relacionais, o olhar a palavra e o toque, conforme foi referido por uma dirigente: "agora começamos a pensar, que a Humanitude não é só o toque, há o olhar e a palavra, portanto há que utilizá-Ios nos cuidados em Humanitude, o toque é um dos pilares não é o todo." (E3).

0 amor, emoção composta pela alegria e confiança, foi percebida pelas

dirigentes a partir dos seguintes depoimentos: "fazemos aquelas comidas elas gostam muito, fazemos uns miminhos doces também." (E1); "Se estivéssemos ali numa lógica de tarefa, não teríamos tido a mesma capacidade de suportar as exigências emocionais que o Covid implica e impõe, 0 amor é a grande estratégia que vem da Humanitude...as técnicas que se aprendem são importantes, mas efetivamente a qualidade da relação, 0 amor que se transmite em cada olhar, em cada toque, em cada palavra que se dirige, que

não infantiliza, que não mortifica, que é pela vida, e que valoriza a utilidade." (E2); "eu tenho um depoimento de um senhor, que infelizmente teve o COVID, que me pediu por tudo, e por várias vezes, que não 0 enviasse para o hospital porque ele sabia que cá iria ser bem cuidado até ao fim, e acabamos por Ihe fazer a vontade." (E3).

Quanto ao otimismo em relação à MCH as dirigentes referiram os seguintes discursos: "mesmo neste contexto de pandemia, os nossos cuidados continuavam a ser cuidados próximos, porque eles têm que o ser" (E1); "a Humanitude tem que renascer em todo seu exponencial, ela nunca morreu, temos que voltar a potenciar e é neste caminho que estamos neste momento, num caminho de reconquista." (E2); "sempre atenta ao que era suposto eu fazer e o que era esperado ser feito, e depois confiar...os pilares da Humanitude, claro, o toque a palavra, o olhar, sim a partir daí tudo acaba por

amenizar, a forma como nós comunicamos com o outro, o que dizemos, geram emoções." (E4).

Na tabela 1 apresentamos as categorias e subcategorias resultantes da análise de conteúdo das respostas das dirigentes das instituições às questões colocadas sobre a percepção das emoções.

Tabela 1 - Categorias, subcategorias e unidades de enumeração relativas às emoções segundo o modelo de Plutchik (2002)

\begin{tabular}{|c|c|c|}
\hline Categorias & Subcategorias & $\begin{array}{l}\text { Unidades de } \\
\text { enumeração }\end{array}$ \\
\hline \multirow[t]{4}{*}{$\begin{array}{l}\text { Emoções } \\
\text { percebidas } \\
\text { em relação à } \\
\text { pandemia }\end{array}$} & $\begin{array}{l}\text { Emoções básicas negativas } \\
\text { (medo, tristeza, angústia, } \\
\text { nojo, tédio, aborrecimento, } \\
\text { antecipação e vigilância) }\end{array}$ & 30 \\
\hline & $\begin{array}{lr}\text { Emoções } & \text { compostas } \\
\text { negativas/díade primária } & \text { pade) } \\
\text { (desprezo, agressividade) }\end{array}$ & 3 \\
\hline & $\begin{array}{l}\text { Emoções } \\
\text { negativas/díade secundária } \\
\text { (fatalismo, desespero e e } \\
\text { descrença) }\end{array}$ & 6 \\
\hline & 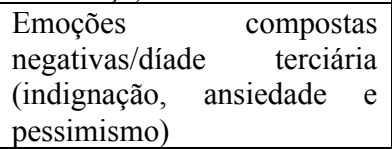 & 8 \\
\hline \multirow{2}{*}{$\begin{array}{l}\text { Contributos } \\
\text { da MCH na } \\
\text { gestão das } \\
\text { emoções } \\
\text { durante o } \\
\text { confinamento }\end{array}$} & $\begin{array}{l}\text { Emoções básicas positivas } \\
\text { (alegria, } \\
\text { confiança, aprovação e } \\
\text { interesse) }\end{array}$ & 13 \\
\hline & $\begin{array}{lr}\text { Emoções } & \text { composta } \\
\text { positivas/díade } & \text { primária } \\
(\text { amor e otimismo) } & \end{array}$ & 9 \\
\hline
\end{tabular}




\section{CONTRIBUTO DA METODOLOGIA DE CUIDADO HUMANITUDE PARA A GESTÃO DAS EMOÇ̃̃ES NA PANDEMIA}

\section{DISCUSSÃO}

Durante o período de confinamento, devido à pandemia do COVID-19, foram evidenciadas, pelos dirigentes das residências para pessoas idosas, as seguintes emoções negativas: medo, tristeza, angústia, nojo, tédio, aborrecimento, antecipação, vigilância, desprezo, agressividade, fatalismo, desespero, descrença, indignação, ansiedade e pessimismo. Também no estudo de Melo, Luz, Henriques e Martins (2020) foi evidenciado que as práticas de cuidados para evitar a contaminação por COVID-19 provocaram sentimentos de solidão, medo, ansiedade e sentimento de abandono, comprometendo os laços de humanitude.

Neste estudo, foi evidenciado que a implementação dos princípios e pilares da $\mathrm{MCH}$ contribuiu para a minimização dessas emoções negativas e potenciou emoções positivas, gerando mais alegria, serenidade, confiança, aprovação, interesse, amor e otimismo em todos os envolvidos. Para amenizar os efeitos negativos advindos da COVID-19, a MCH, pode ser uma referência na assistência à saúde destas pessoas, que estão em situação de grande fragilidade e vulnerabilidade, por permitir a operacionalização da humanização e dignificação da pessoa cuidada em qualquer contexto (Melo et al., 2019). Estes resultados corroboram outros estudos ao evidenciarem que as práticas para preservar os laços de humanitude em situação de COVID-19 foram a intencionalidade e manutenção dos pilares relacionais, nomeadamente, na forma de olhar, abordando a pessoa de frente no seu campo visual; na forma e conteúdo da comunicação verbal, utilizando um tom de voz suave e na apresentação do cuidador; e 0 toque, com movimentos amplos e suaves (Melo et al., 2020). Também Honda, Ishikawa, Takebayashi e Tiemey (2016) salientam, que em situações e grande vulnerabilidade da pessoa cuidada, a manutenção de pelo menos dois pilares relacionais, contribui para o bem-estar dos idosos, o qual se estende aos profissionais, levando a um aumento da sua satisfação (Phaneuf, 2007; Pereira, Gomes \& Galvão, 2012; Simões, Salgueiro \& Rodrigues, 2012; Honda et al., 2016).

Temos de aprender a embalar a fragilidade com profissionalismo, para ajudar cada pessoa a reencontrarse com as memórias emocionais positivas e a criar novas, porque à beira do fim de vida tanta coisa começa (Martins, Araújo \& Melo, 2017).

Apesar do presente estudo evidenciar um esforço inovador em contexto nacional e internacional, dado não se terem identificado estudos nesta área, apontam-se algumas limitações na sua consecução, nomeadamente 0 tamanho reduzido da amostra, o que impossibilita a generalização dos dados obtidos. Assim, sugerimos a realização de mais estudos de investigação multicêntricos, no sentido de se identificarem as emoções que os profissionais de saúde vivenciam na situação de pandemia COVID-19, evidenciando-se o potencial da apropriação da MCH na gestão das emoções, contribuindo para um cuidado diferenciador e humanizado.

\section{CONCLUSÕES}

A pandemia, que nos assola há mais de um ano, tem de nos levar a uma mudança de paradigma - que a epidemia da solidão se transforme na epidemia da preservação da humanitude na pessoa cuidada. A moral "anárquica" deste vírus duro e cruel, é que, por amor, juntos, podemos legitimamente sarar e cuidar do sofrimento.

As emoções influenciam continuamente nessa relação com o outro e, para um

profissional da área da saúde, algumas influências podem interferir em suas relações

com a pessoa cuidada. Em contrapartida, o profissional que gere bem as suas emoções

exerce melhor as suas atividades, pois é capaz de lidar com as emoções e principalmente com os sentimentos despertados por elas.

Torna-se, pois, fundamental a apropriação dos principios da $\mathrm{MCH}$, por parte

dos cuidadores, orientadores da prática de cuidados humanizados, facilitadores da interação com a pessoa cuidada, promovendo sentimentos de bem-estar, mesmo em situação de grande vulnerabilidade e fragilidade, como é o caso da pandemia por COVID-19, vivenciada pelos idosos institucionalizados. 


\section{REFERÊNCIAS BIBLIOGRÁFICAS}

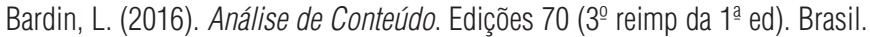

Henriques, L., Dourado, M., Melo, R., \& Tanaka, L. (2019). Implementação da Metodologia de Cuidado Humanitude: contribuição para a qualidade da assistência à saúde. Rev. Latino-Am. Enfermagem, 27 (e3123).

Honda, M. et al. (2016). Reduction of behavioral psychological symptoms of dementia by multimodal comprehensive care for vulnerable geriatric patients in an acute care hospital: A case series. Cases Report in Medecine, p. 1-4, 2016. DOI: 10.1155/2016/4813196. Disponível em: https://doi.org/10.1155/2016/4813196.

Martins, A., Araújo, J., \& Melo, R. (2017). Estimulação multissensorial durante o cuidado de higiene e conforto. in R. C. Melo, Higiene e Conforto: Da tarefa ao cuidar com Humanitude. Série Monográfica Educação e Investigação em Saúde. Coimbra, Portugal: Unidade de Investigação em Ciências da Saúde: Enfermagem (UICISA: E) \Escola Superior de Enfermagem de Coimbra (ESEnfC), 2017. p. 145-159.

Melo, R. C. C. P. de., Costa, P. J., Henriques, L. V. L., Tanaka, L. H., Queirós, P. J. P., \& Araújo, J. P. (2019). Humanitude in the humanization of elderly care: experience re-ports in a health service. Revista Brasileira de Enfermagem, 72(3),825-29. Epub June 07, 2019. doi: https://doi.org/10.1590/0034-7167-2017-0363.

Melo, R. C. C. P. de., Luz, H.A., da., Henriques, L.V.L., \& Martins, A. (2020). Como preservar os laços de humanitude em pessoas idosas em situação de Covid-19. (2020b). Revista Cientifica Internacional RevSALUS, Suplemento n-2, p. 138, setembro, 2020.

Pereira, F.; Gomes, M. J.; Galvão, A. (2012) - Ética e humanitude no cuidado do idoso. In. Pereira, F. - Teoria e Prática da Gerontologia: Um Guia para Cuidadores de Idosos. 1르. Ed. PsicoSoma.

Phaneuf, M. (2007). Le concept d humanitude: une application aux soins infirmiers généraux. Disponivel na WWW: URL: http://pagesperso-orange.fr/ cec-formation.net/phaneuf.pdf

Plutchik, R. (2002). Emotions and life: Perspectives from psychology, biology and evolution. Washington, DC: American Psychological Association.

Rispali, D. (2003). Conhecer-se melhor para melhor cuidar: uma abordagem do desenvolvimento pessoal em cuidados de enfermagem. Lusociência, Loures.

Simões, M. M. M. (2013). Cuidar em Humanitude: Método de Gineste e Marescotti Aplicado a Pessoas Internadas em Cuidados Continuados [Dissertação de Doutoramento, Programa de Doutoramento em Enfermagem. Universidade Católica Portuguesa, Instituto de Ciências da Saúde]. Disponível em http://repositorio.ucp.pt/handle/10400.14/13913.

Simões, M., Salgueiro, N., \& Rodrigues, M. (2012). Cuidar em Humanitude: estudo aplicado em cuidados continuados. Revista de Enfermagem Referência, 6, 81-93. Consultado em 19 dezembro 2020. Disponível em http://www.scielo.mec.pt/pdf/ref/vserllln6/serllln6a08.pdf .

Teixeira, C. F. de S., Soares, C. M., Souza, E. A., Lisboa, E. S., Pinto, I. C. de M., Andrade, L. R. de., \& Espiridião, M. A. (2020). A saúde dos profissionais de saúde no enfrentamento da pandemia de Covid-19. Ciência \& Saúde Coletiva, 25(9), 3465-3474. Epub August 28, 2020. doi: https://doi.org/10.1590/141381232020259.19562020.

Zhang, J., Wu, W., Zhao, X., \& Zhang, W. (2020). Recommended psychological crisis intervention response to the 2019 novel coronavirus pneumonia outbreak in China: a model of West China Hospital. Precision Clinical Medicine, pbaa006. https://doi.org/10.1093/pcmedi/pbaa006. 
